\title{
Adolescência e sexualidade no cotidiano da equipe de enfermagem do serviço de atenção básica de saúde
}

\section{Adolescence and sexuality in the everyday lives of the nursing team of the basic health care service}

\author{
Tatiana Yoriko Tomita ${ }^{1}$; Rosângela Aparecida Pimenta Ferrari ${ }^{2}$
}

\begin{abstract}
Resumo
Trata-se de uma investigação descritiva quantitativa para identificar a percepção da equipe de enfermagem, do Serviço de Atenção Básica de Saúde, a respeito das questões referentes à sexualidade e a adolescência. Participaram da pesquisa 57 profissionais, (52\%) enfermeiros e (43,9\%) auxiliares de enfermagem. O sexo feminino foi predominante, $84 \%$. A maioria (54\%) refere ser da religião católica. A prática da masturbação é uma forma natural de conhecer o corpo para $84 \%$ da equipe. A homossexualidade é uma escolha como outra qualquer para $56 \%$ dos católicos, enquanto que, $42 \%$ dos evangélicos consideram-na um distúrbio psicológico. Referem que a iniciação sexual deve acontecer entre 20 e 24 anos de idade (61\%) e ser com alguém que se sinta grande atração. Quem deve conversar sobre sexualidade com os adolescentes são os pais e os profissionais da educação e da saúde (96\%). Quanto à abordagem dos adolescentes no serviço, $63 \%$ se sentem preparados mesmo que $37 \%$ consideram ser difícil responder as questões sobre a temática por não fazer parte do dia-a-dia. Os profissionais deste estudo demonstram responsabilidade quanto ao processo educativo e preventivo, mas ainda alguns tabus e preconceitos estão presentes e podem interferir no processo de educação em saúde quanto à prevenção da gravidez não planejada e dos riscos da transmissão das DST e da aids.
\end{abstract}

Palavras-chave: Adolescência. Sexualidade.Enfermagem. Atenção Básica de Saúde.

\begin{abstract}
This is a descriptive-quantitative survey to identify the perception of the nursing team of the Basic Health Care Service about questions concerning sexuality and adolescence. Fifty-five professionals took part in this research: $(52 \%)$ nurses and $(43,9 \%)$ nursing assistants. The female sex was predominant, $84 \%$. Most of them (54\%) claims to be Catholic. Masturbation practice is a natural way to know the body for $84 \%$ of the team. Homosexuality is a choice as any other one for $56 \%$ of the Catholic people, whereas $42 \%$ of the evangelicals consider it as a psychological disorder. It is mentioned that sexual initiation should happen between the ages of 20 to 24 years old (61\%) and it should be with someone they feel really attracted to. It is considered that those who should talk about sexuality with adolescents are the parents and the health and education professionals $(96 \%)$. As for the approach to adolescents at work, $63 \%$ consider themselves prepared even though $37 \%$ consider it difficult to answer questions about the theme for not being a part of their everyday lives. The professionals of this study demonstrate responsibility as for the educational and preventive process, but they all agree that there still exist some taboos and prejudice which may interfere in the process of health education, concerning non-planned pregnancy prevention and risks of Sexually Transmitted Diseases (STDs) and AIDS.
\end{abstract}

Key words: Adolescence. Sexuality. Nursing. Basic Health Care.

1 Estudante do $4^{\circ}$ Ano do Curso de Enfermagem - Departamento de Enfermagem - Centro de Ciências da Saúde - Universidade Estadual de Londrina, Paraná, Brasil.

2 Enfermeira, Docente do Departamento de Enfermagem - Área da Saúde da Criança e do Adolescente - Centro de Ciências da Saúde - Universidade Estadual de Londrina, Londrina, Paraná, Brasil. Endereço: Av. Robert Koch, nº 60, Vila Operária, $1^{\circ}$ Andar, CEP: 86038-440 - Londrina - Paraná, Brasil. Email: ropimentaferrari@ uel.br. 


\section{Introdução}

A fase da adolescência é considerada um dos períodos do desenvolvimento humano em que ocorrem várias mudanças, entre as quais, corporais, emocionais, e também sócio-culturais.

Dentre as várias mudanças nesta fase da vida "a mais conflituosa é a sexualidade, pois está relacionada com muitas crises e preocupações, impregnadas de valores morais e preconceitos, herdados da família e da sociedade despertando uma situação-problema aos olhos do jovem e da família" (OLIVEIRA, 1995, p.95).

Villela e Arilha (2003) referem que quando se fala de sexualidade não se deve fazer referência apenas ao ato sexual, mas ao conjunto de fantasias e idéias que cada um constrói sobre si e para si, em função daquilo que supõe levar ao gozo. A sexualidade constitui um importante dispositivo social de controle sobre as pessoas, normas a respeito de com quem é permitido ou proibido ter relações sexuais, conforme cada sociedade e momento histórico.

Segundo Furlani (2003, p.67), a sexualidade "é um aspecto intrínseco aos seres humanos, em todas as épocas de sua vida e a educação sexual deve-se caracterizar pela continuidade, baseada por princípios claros de um processo permanente, desestabilizando 'verdades únicas', os restritos modelos da sexualidade normal, mostrando o jogo de poder e de interesses envolvidos na intencionalidade de sua construção e, depois, apresentar as várias possibilidades sexuais presentes no social, na cultura e na política da vida humana, problematizando o modo como são significados e como produzem seus efeitos sobre a existência das pessoas".

Em virtude do 'desconhecimento' da sexualidade, tanto pelos pais, quanto pelos educadores e profissionais da saúde, cria-se um emaranhado de dúvidas, preconceito e preocupações acerca da temática, e isso influencia negativamente no comportamento e atitude dos jovens.

Mas quando o jovem não tem que esconder ou esconder-se da sexualidade vivenciando-a sem culpa e pecado, segredo e mentira, ele pode buscar e fazer usufruto conscientemente sem correr riscos e praticála de forma segura (VILLELA; ARILHA, 2003).

Os profissionais que atuam no Serviço de Atenção Básica de Saúde podem atuar e desenvolver ações educativas em saúde, num processo dinâmico e contínuo, para colaborar com este grupo etário no intuito de diminuir tais riscos, mas para isto, eles devem estar preparados para abordar esta clientela e os temas referentes à sexualidade humana e a fase da adolescência.

Nesse sentido, o presente estudo, teve como objetivo identificar a percepção dos enfermeiros e auxiliares de enfermagem do Serviço de Atenção Básica de Saúde sobre sexualidade e adolescência.

\section{Metodologia}

Trata-se de uma investigação descritiva quantitativa, realizada com enfermeiros e auxiliares de enfermagem das Unidades Básicas de Saúde UBS, da Região Sul do município de Londrina, no período de junho a julho de 2005.

O município de Londrina possui um sistema de saúde municipalizado. A Secretaria Municipal de Saúde conta com 52 UBS, que são distribuídas na cidade da seguinte forma: 8 na Região Sul, 8 na Região Central, 8 na Região Norte, 8 na Região Leste, 7 na Região Oeste e 13 na Região Rural.

Dentre as regiões do município, a Sul foi o objetivo do estudo, por ser a segunda maior região e possuir uma população adolescente de $23,4 \%$ conforme dados do Sistema de Informação de Atenção Básica SIAB (LONDRINA, 2005).

A pesquisa foi realizada aplicando-se um questionário com perguntas de múltipla escolha sobre questões referentes à sexualidade humana e à fase da adolescência. $\mathrm{O}$ instrumento foi preenchido pelos profissionais no local de trabalho e posteriormente recolhido pelos pesquisadores.

Os dados obtidos foram classificados e submetidos ao cálculo de porcentagem e a estudos de correlação, 
utilizando-se o programa Excel, e os resultados apresentados de forma descritiva e em gráficos.

A pesquisa seguiu todas as normas da Resolução ${ }^{\circ}$ 196, de 10 de outubro de 1996, do Conselho Nacional de Saúde (BRASIL, 1996). Foi aprovada pelo Comitê de Ética em Pesquisa da Universidade Estadual de Londrina - UEL, parecer número 115/05.

\section{Análise e Discussão dos Resultados}

As nove UBS da região Sul do município, contam com 125 profissionais de enfermagem, sendo 27 enfermeiros e 98 auxiliares de enfermagem. Destes profissionais, $57(45,6 \%)$ aceitaram participar da pesquisa, representando 14 (52\%) enfermeiros e 43 $(43,9 \%)$ auxiliares de enfermagem.

A idade entre os 57 participantes variou de 24 a 50 anos, predominando a faixa etária de 31 a 40 anos (44\%). Quanto ao sexo, o feminino representou $84 \%$ e masculino $16 \%$. Com relação ao estado civil $46 \%$ casados e $28 \%$ solteiros. A religião mais referida é a católica (54\%), seguida pela evangélica (33\%).

A fase da adolescência e a sexualidade para os enfermeiros e auxiliares de enfermagem

A adolescência para $56 \%$ dos profissionais é a faixa etária dos 12 a 18 anos de idade e pouco mais de $30 \%$ considera a idade entre 10 a 19 anos. No Brasil, o Estatuto da Criança e do Adolescente ECA (BRASIL, 1991), determina a adolescência a fase dos 12 aos 18 anos de idade, enquanto que o Ministério da Saúde baseado na Organização Mundial da Saúde - OMS, considera a idade dos 10 aos 19 anos que abrange a pré-adolescência - faixa etária de 10 a 14 anos e a adolescência propriamente dita - dos 15 aos 19 anos (ORGANIZAÇÃO MUNDIAL DA SAÚDE, 1995).

Cabe salientar que a presente pesquisa baseou-se na fase da adolescência considerada pela OMS (1995).
Pode-se observar que é predominante o conhecimento dos profissionais a respeito da fase de início e fim da adolescência, nos parâmetros do ECA, e não na OMS. Tal fato pode significar que os limites que correspondem este grupo etário não tem sido discutidos na área da saúde, bem como a precocidade, ao longo das últimas décadas, do desenvolvimento e crescimento físico e transformações psicossociais deste grupo etário, que pela OMS (1995) tem início aos 10 anos de idade.

Para Outeiral (1994), a adolescência divide-se em três etapas, de início e fim não muito precisos, em que algumas características se confundem e flutuações progressivas e regressivas se sucedem. A primeira, a adolescência inicial (de 10 a 14 anos), é caracterizada basicamente pelas transformações corporais e as alterações psíquicas derivadas deste acontecimento. A segunda, a adolescência média (de 14 a 16 ou 17 anos), tem como elemento central as questões relacionadas à sexualidade, em especial, a passagem da bissexualidade para a heterossexualidade. A terceira, a adolescência final (de 16 ou 17 anos até 20 anos), apresenta vários elementos importantes, entre os quais o estabelecimento de novos vínculos com os pais, a questão profissional, a aceitação do novo corpo e dos processos psíquicos do mundo adulto.

Quanto ao desenvolvimento e crescimento físico dos adolescentes, ocorre a formação dos caracteres sexuais, nos garotos a semenarca e nas garotas a menarca, anunciando que estão fisiologicamente reprodutivos.

A partir deste momento, a sexualidade torna-se mais evidente, este grupo etário, poderá iniciar vida sexual e se não utilizarem métodos de contracepção ou de barreira estarão predisponentes aos agravos referentes à gravidez não planejada, às doenças sexualmente transmissíveis - DST e à aids.

Segundo Huertas (2001), a média de iniciação sexual nos países da América Latina e Caribe, foi de 15,7 anos para homens e 17,0 anos de mulheres e no Brasil esta média é de 14,6 anos de idade (BRASIL, 2003). 
No município de Londrina, pesquisa realizada por Oliveira (2002), com 1.642 adolescentes de 15 a 19 anos em treze escolas públicas da cidade, representando todas as regiões, demonstrou que a média da iniciação sexual foi de 14,2 anos para os meninos e 15,1 para as meninas.

Estudos tanto na América Latina e Caribe como no Brasil, têm demonstrado que a cada ano os adolescentes estão precocemente iniciando a vida sexual, principalmente os de baixa escolaridade (FERRAZ; FERREIRA, 1998; BEM-ESTAR FAMILIAR NO BRASIL - BEMFAM, 1999; CAMACHO, 2000; GAMA; SZWARCWALD; LEAL, 2002; LUNARDELLI, 2002; OLIVEIRA, 2002; SIMÕES et al., 2003; PAIVA et al., 2003).

Portanto, parece ser evidente que quanto antes se discutir sexualidade menor poderá ser a probabilidade da precocidade da iniciação sexual e dos agravos a ela relacionada.

A idade ideal para se iniciar a conversa sobre sexualidade é a escolar (dos 6 aos 9 anos) para $45 \%$ dos enfermeiros e auxiliares de enfermagem, mas para $37 \%$ a fase ideal é a adolescência (dos 10 aos 19 anos).

Para discutir e falar sobre a temática sexualidade, mais de $96 \%$ a equipe de enfermagem considera que a responsabilidade é tanto dos professores, pais ou responsável, como dos profissionais de saúde (médicos, enfermeiros, auxiliares de enfermagem e psicólogos).

Pode-se evidenciar que este resultado demonstra o quanto que a equipe está consciente do seu papel no processo educativo e preventivo, mas parece não estar claro ainda, que existe uma lacuna entre o achar e o fazer. $\mathrm{O}$ adolescente não tem encontrado nem na família e nem nas instituições de educação e saúde, ajuda e esclarecimento sobre questões pertinentes à sexualidade, pois os índices de gravidez não planejada, DST e aids continuam crescentes neste grupo etário, como referido anteriormente.
Pesquisas têm demonstrado que as fontes de informação dos adolescentes são predominantemente os amigos, mas nem sempre estes contam com informações seguras (JEOLÁS; FERRARI, 2003; ABRAMOVAY; CASTRO; SILVA， 2004; ABRAMO; BRANCO, 2005).

Dentre as questões pertinentes à sexualidade na adolescência, a prática da masturbação é considerada por $84 \%$ dos enfermeiros e auxiliares de enfermagem uma forma natural para conhecer o corpo. Isso indica que está desmistificada a noção desse ato como pecado. Ele é reconhecido como uma prática comum entre as pessoas, principalmente entre os adolescentes.

Segundo Oliveira (1995), a postura dos pais em relação à temática será determinante nas atitudes dos filhos à sua própria sexualidade, em que a masturbação não deve ser encarada como algo sujo e a orientação sexual deve ser dirigida apenas aos aspectos negativos do sexo.

Os resultados da pesquisa de Jeolás e Ferrari (2003) mostram que há diferenciação na forma como os adolescentes vivenciaram esta prática, pois $80 \%$ dos garotos praticam-na e apenas $25 \%$ das garotas o fazem, e $70 \%$ delas não a utilizam como forma de explorar seu próprio corpo.

Se para os profissionais deste estudo a masturbação é uma prática natural na vivência da sexualidade humana, a homossexualidade parece não ser, pois $56 \%$ da equipe pertencente à religião católica e $42 \%$ à religião evangélica consideram uma escolha como outra qualquer, enquanto que, para $28 \%$ e $42 \%$ um distúrbio psicológico, respectivamente (Figura 1). Ainda na mesma figura, pode-se observar que $30 \%$ dos evangélicos não responderam a pergunta sobre o tema. 


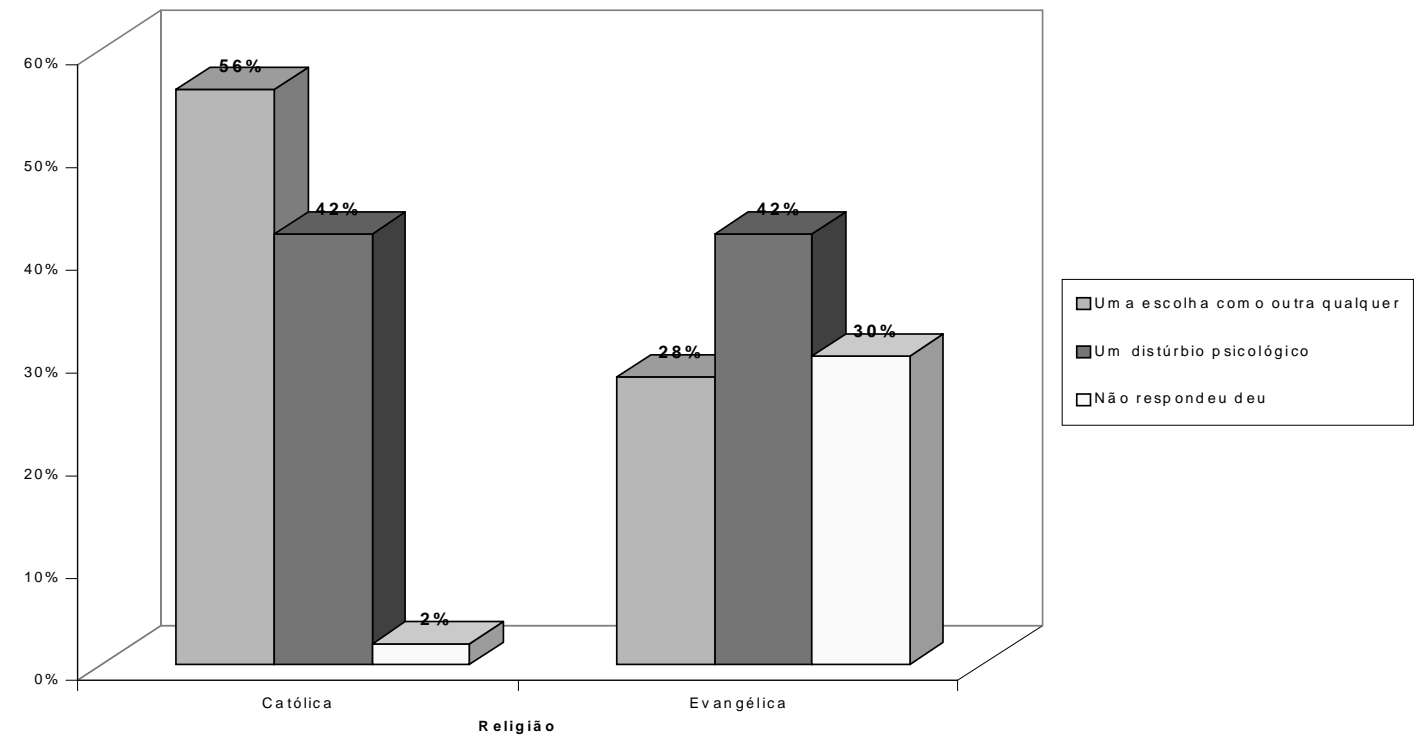

Figura 1. Distribuição dos enfermeiros e auxiliares de enfermagem quanto à concepção sobre a homossexualidade de acordo com a religião, Londrina, 2005.

Em países desenvolvidos, a aceitação da homossexualidade progrediu de maneira bem nítida, mas há ainda diversas manifestações de rejeição que continuam a criar um contexto de vida bastante particular para eles, como alguns meios profissionais e espaços geográficos que são poucos tolerantes (BOZON, 2004).

A vergonha ou o constrangimento, de falar sobre questões que envolvam a sexualidade humana e as opções sexuais de cada indivíduo está relacionado ao tabu e à dificuldade de abordar o tema.

Segundo Rena (2001, p.224) "é preciso considerar as intrincadas relações subjacentes ao discurso sobre sexo/sexualidade e todos os sentimentos que esta prática discursiva pode mobilizar em nossa sociedade". Isto reflete o processo de regulação da sexualidade nas sociedades ocidentais, largamente analisado por Foucault (1984)".

Para Jeolás e Ferrari (2003, p.627), "nas questões que permeiam a sexualidade e os riscos que a envolve devem ser desconstruídas as metáforas negativas, desfazer medos e tabus para que jovens se tornem sujeitos de sua própria sexualidade".
Ainda para estas autoras, para que ocorra este espaço de discussão, os profissionais "não poderão se comportar como transmissor vertical de conhecimento, nem tampouco transmitir valores pessoais à sexualidade, empreendendo um exercício disciplinar que assegura uma determinada manutenção do status sexual e da sexualidade da ordem social estabelecida. Portanto, o papel dos profissionais deverá ser o interlocutor de facilidades da discussão e da reflexão".

Quanto à iniciação sexual, 61\% dos profissionais deste estudo referem que deve acontecer dos 20 aos 24 anos.

Pode-se observar que esta faixa etária está longe dos padrões encontrados na sociedade, em que o ato sexual é cada vez mais precoce, como referido anteriormente.

$\mathrm{Na}$ figura 2, pode-se observar que a primeira relação sexual do adolescente para $44 \%$ dos profissionais católicos e $37 \%$ dos evangélicos deve ser com alguém que sinta grande atração e para $25 \%$ e $21 \%$ ser com namorado fixo, respectivamente. Mas, para $26 \%$ dos evangélicos o ato sexual deve ser somente após o casamento. 


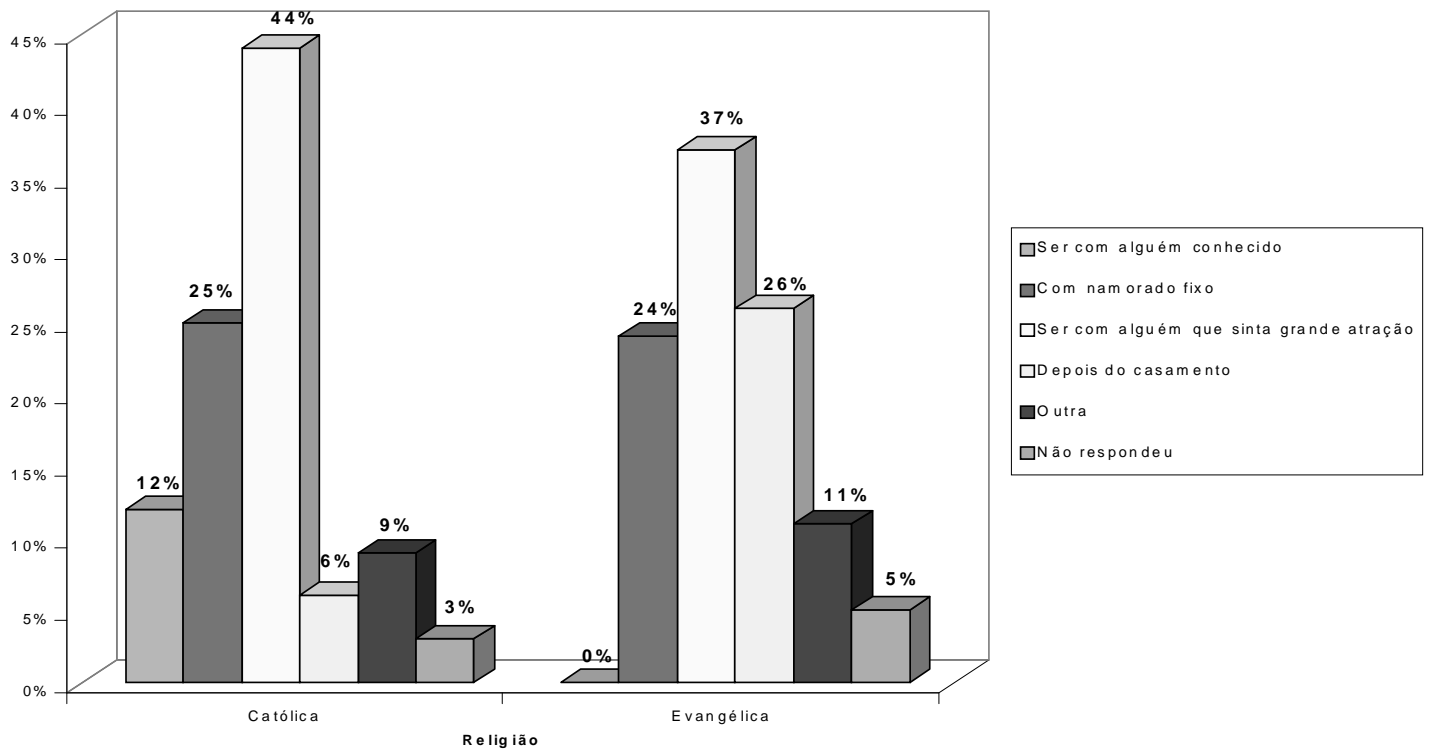

Figura 2. Distribuição dos enfermeiros e auxiliares de enfermagem sobre com quem o adolescente deve ter a primeira relação sexual de acordo com a religião, Londrina, 2005.

Segundo Bozon (2004), nas culturas latinas e latino-americanas, o controle social visa retardar, o quanto possível, a entrada das mulheres na sexualidade, a fim de preservar sua virgindade até o casamento. A perda desta, antes do casamento permaneceu (e ainda permanece em alguns lugares) uma transgressão grave. Resquícios desse pensamento, ainda pode prevalecer, como um padrão imposto pela religião e sociedade.

Dentre os padrões de comportamento sexual, literalmente derrubados a partir da década de setenta, talvez os mais conseqüentes sejam a valorização positiva da virgindade e a proibição das relações sexuais fora do casamento. Ultrapassado esses tabus, os jovens passaram a ser empurrados para o sexo com o pretexto de ser uma forma de exercício do direito à liberdade e à modernidade. Neste contexto substitui-se o 'tabu da não virgindade' confundindo-se 'liberdade de opção' com 'imposição de opção’ (OLIVEIRA, 1995).

Os jovens, muitas vezes, não têm oportunidade de esclarecer suas dúvidas pessoais, e, ao mesmo tempo, logo iniciam sua vida sexual. Só quando a gravidez ocorre é que pais, professores e profissionais de saúde percebem que sua atitude de 'tapar o sol com a peneira' na verdade não leva a lugar nenhum. Ao mesmo tempo em que a sociedade condena iniciação sexual antes do casamento, há um incentivo ao erotismo, por intermédio dos meios de comunicação.

Ao se concretizar práticas de discussão sobres sexo, sexualidade e gênero desde a fase escolar, referido anteriormente, possivelmente diminuirá o turbilhão de opiniões e informações contraditórias, que para os adolescentes não os direcionam para uma vida sexual saudável e sem riscos.

Para Bruns (1995), a identidade sexual e social de cada um de nós é construída segundo a família (uma miniatura da sociedade), por meio da visão de mundo que recebemos dos pais, ou seja, por meio de seu sistema de valores, e na escola em que o jovem vivencia uma realidade diferente daquela do ambiente familiar.

Segundo Ferrari (2004), para lidar com as questões que afligem a saúde do adolescente deve-se incorporar, no direcionamento da assistência, discussão sobre estilo de vida em função do que se pode identificar como agravos à saúde mais importantes nesta fase da vida. 
Para Ayres e França Júnior (1996, p.83) “[...] um dos maiores obstáculos ao trabalho com esta população, é a forma estereotipada e naturalizada com que tem tratado os jovens em nossos serviços de educação e saúde, sendo abordado como um conjunto de fenômenos biológico e universal".

Quanto ao cenário educacional, ao longo dos anos tornou-se um lugar privilegiado para desenvolver a educação sexual, mas em certos países em que a Igreja Católica exerce forte influência, esta atividade é dificilmente aceita. Nos EUA a orientação sexual assinala uma cultura em que a sexualidade é considerada de risco reforçando o controle moral. Já nos países europeus, diz respeito a uma questão mais social do que moral ou política, ela tem como objetivo a formação equilibrada da personalidade um aprendizado das relações, de acordo com o princípio de igualdade e responsabilidade nas relações entre os sexos (BOZON, 2004).

Qualquer que seja o espaço e a profissão de origem, quem trabalha com grupos de adolescentes deve conhecer as características básicas do grupo, ter uma clara disposição para o trabalho participativo e estar consciente de sua função dentro dos vários contextos da comunidade em que estes se inserem (FERRARI, 2004).

Todos os profissionais têm a responsabilidade na educação sexual dos jovens, mas se o conceito de equilíbrio de personalidade, igualdade e responsabilidade não for aceito como objetivo a ser transmitido aos jovens, dificilmente ocorrerá mudança do comportamento.

Com relação ao método mais eficaz para prevenir a gravidez na adolescência, a figura 3, mostra que $60 \%$ dos profissionais consideram o preservativo masculino ou feminino, por ser o mais prático e acessível, prevenindo além da gravidez as doenças sexualmente transmissíveis.

Chama a atenção, ainda na figura 3, que $18 \%$ dos profissionais consideram abstinência sexual e 7\% o ato sexual somente no casamento como método, mesmo existindo várias opções para a anticoncepção.

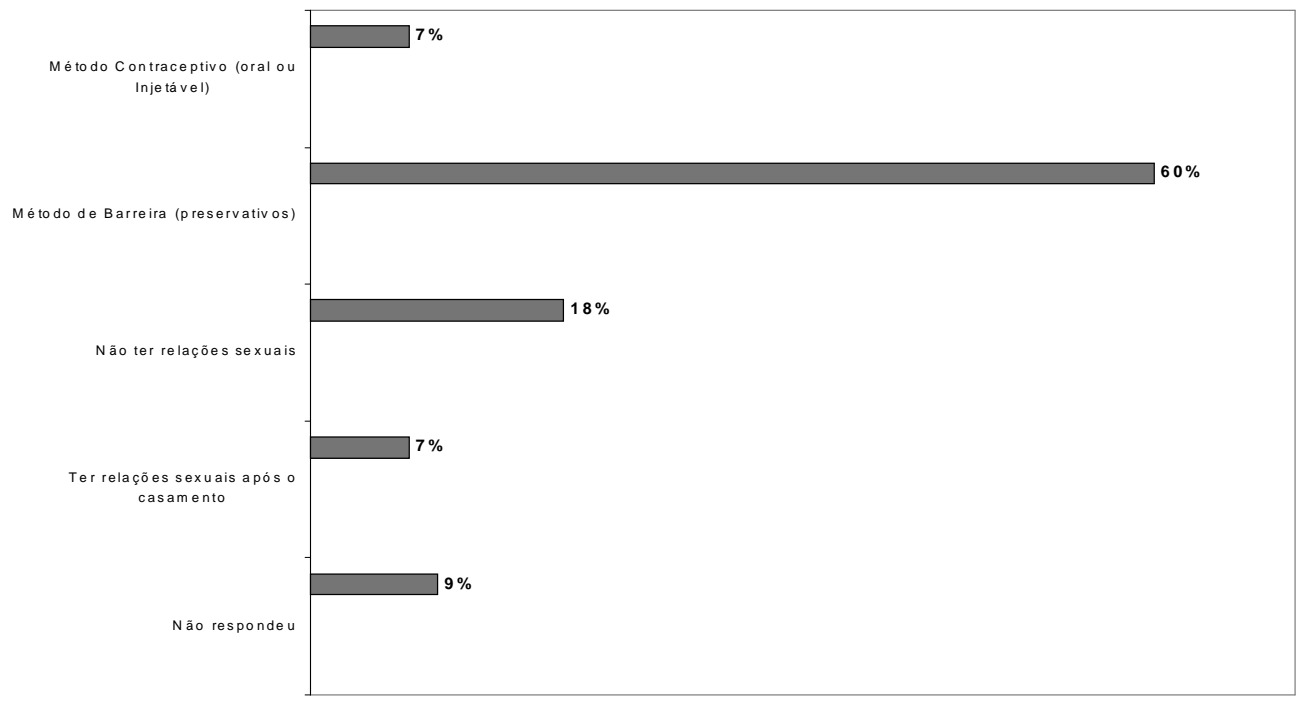

Figura 3. Distribuição dos enfermeiros e auxiliares de enfermagem quanto às respostas do método contraceptivo ou de barreira mais eficaz para prevenir gravidez entre os adolescentes, Londrina, 2005. 
A pesquisa que Camacho Hubner (2000), realizou com adolescentes da América Latina e Caribe, acerca do uso de método contraceptivo na primeira relação sexual, evidencia que apenas $23 \%$ usava algum método, sendo o oral mais utilizado. A freqüência do uso de algum método contraceptivo aumentou entre os adolescentes com maior idade.

Por outro lado, a pesquisa de Paiva et al. (2003), no Brasil, demonstrou que entre os brasileiros/as mais jovens continua crescente o uso de preservativo na primeira relação sexual, bem como o seu uso consistente (uso em todas as relações sexuais), tanto com parceiros estáveis, como com parceiros eventuais, especialmente entre os jovens de níveis mais altos de escolaridade.

Segundo os mesmos autores, nos grupos menos escolarizados, as meninas, em todas as faixas etárias, mantêm-se como grupo mais exposto, com menor acesso ao preservativo gratuito e, quando referiram o uso do preservativo, esse grupo foi mais inconsistente (uso em algumas relações sexuais) do que o grupo dos meninos.

Com relação ao uso inconsistente do preservativo, pelas meninas, os resultados da pesquisa de Oliveira (2002), também apontam que os meninos usam com maior frequiência o preservativo nas relações sexuais do que as meninas.

Os dados da pesquisa comparativa do Demography and Health Survey (DHS) apud Almeida et al. (2003) em 37 países em desenvolvimento, apontam que quase todos os adolescentes pesquisados referiram conhecer pelo menos um método contraceptivo, mas seu uso foi de pequena magnitude e irregular, principalmente nos estratos socioeconômicos mais precários e com baixa escolaridade. Estes dados foram semelhantes aos estudos realizados no Brasil (BÉRIA, 1998; SZWARCWALD et al., 2000; SILVA et al., 2002; GUIMARÃES; VIEIRA; PALMEIRA, 2003).

Estima-se que 10 milhões de adolescentes vivam hoje com o Vírus Imunodeficiência Humana - HIV ou estão propensos a desenvolver a aids no período dos próximos três a quinze anos. Aproximadamente $80 \%$ das transmissões do HIV no mundo ocorrem por sexo desprotegido. $\mathrm{O}$ adolescente é mais propenso a dispensar o preservativo ou porque não tem acesso a ele ou porque não é capaz de convencer o parceiro ou parceira da necessidade do seu uso, entre outras causas. Na presença de uma DST, o risco de transmissão da aids é três a cinco vezes maior (BRASIL, 2003).

Com relação aos grupos de maior risco em adquirir doença sexualmente transmissível e aids, mais de $80 \%$ dos enfermeiros e auxiliares de enfermagem deste estudo referem que qualquer pessoa, independente de sua escolha sexual, hábitos e estilo de vida é suscetível ao contágio, basta não utilizar preservativo masculino ou feminino nas relações sexuais. Mas ainda, 37\% dos profissionais consideram que por ter um relacionamento estável com um parceiro fixo não está suscetível a contrair essas doenças.

Os profissionais destes estudos responderam à uma questão, com a qual se buscou saber se o fato de se ter um parceiro fixo não torna o adolescente menos susceptível às DST e à Aids, mesmo que ele deixe de usar o preservativo. As respostas não diferem das pesquisas de base qualitativa, acerca da consistência do uso do preservativo entre os adolescentes, realizadas por Paiva (1994), Jeolás (1999), Monteiro (1999), Jeolás e Ferrari (2003), que demonstram que entre os adolescentes o não uso do preservativo justifica-se por se conhecer o parceiro, ter um só parceiro e confiar no parceiro.

Com relação ao fornecimento de preservativo masculino na UBS aos garotos, $37 \%$ dos profissionais referiram distribuí-lo para adolescentes com 12 anos de idade e $54 \%$ com 15 anos de idade.

Quanto à orientação para as garotas sobre o uso do preservativo feminino, $21 \%$ dos profissionais referem que as orientam à partir dos 12 anos de idade, $16 \%$ dos 13 anos e $25 \%$ não responderam a questão. 
As respostas acerca do que se considera ato sexual entre parceiros foram variadas: para 35\% é penetração vagina-pênis, mas $18 \%$ responderam ser o sexo oral e penetração vagina-ânus-pênis. Já 25\% dos profissionais não responderam à questão (Figura 4).

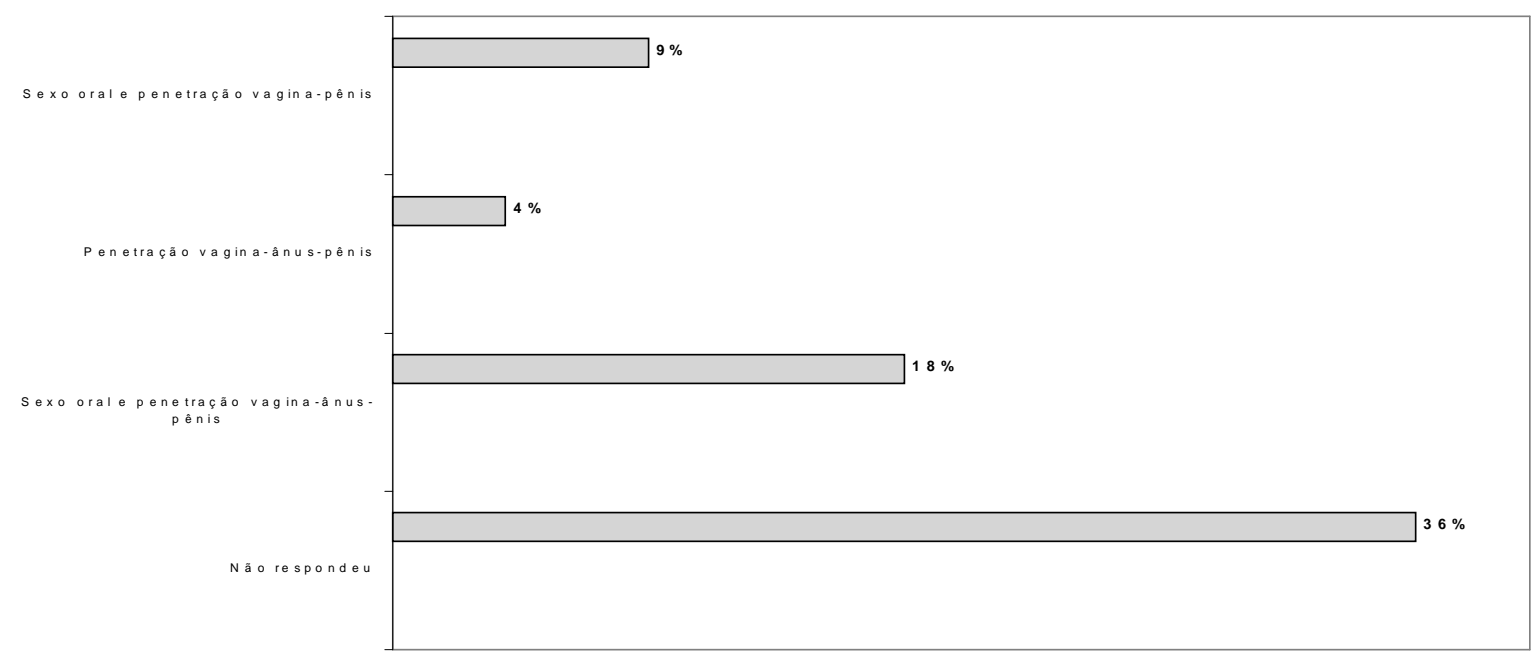

Figura 4. Distribuição dos enfermeiros e auxiliares de enfermagem quanto às respostas sobre o ato sexual entre os parceiros, Londrina, 2005.

Para Heilborn e Brandão (1999), temas como sexualidade ao serem investigados, só fazem sentido somente a partir da teia de significados e relações sociais que os sustentam em um determinado contexto. Assim, o que é sexo para um certo grupo não necessariamente o é para outro e os nexos estabelecidos entre essa dimensão e as demais da vida social também variam.

A sexualidade serve, freqüentemente, de razão para legitimar realidades cujos fundamentos não decorrem de sua ordem, quanto ao fato de que ela pode ser abordada de diferentes ângulos e que sua delimitação ou conceituação depende e pode variar de acordo com os esquemas conceituais utilizados (LOYOLA, 1999).

Cabe salientar que as formas de ato sexual entre os adolescentes determinam a crescente incidência da aids no sexo feminino, na faixa etária de 13 a 19 anos, pois cerca de $86,2 \%$ das mulheres adquirem a aids por relação sexual. Já a principal via de transmissão da aids entre homens é a relação sexual (58\%), ocorrendo esta em $25 \%$ dos casos por relações heterossexuais (BRASIL, 2003).
Com relação ao comportamento sexual dos adolescentes, $53 \%$ dos profissionais da religião evangélica referem que o garoto não previne a gravidez porque não se cuida usando o preservativo, já os da religião católica $41 \%$ consideram que o garoto só quer transar e não se importa com risco de engravidar a garota.

Quanto ao motivo pelo qual a adolescente engravida, mais de $55 \%$ dos profissionais do sexo masculino e $48 \%$ do sexo feminino consideram que elas não se cuidam usando o método contraceptivo ou de barreira. Ainda, 29\% referem que a adolescente não acredita que na primeira relação sexual poderá engravidar.

Cabe ressaltar que quase a totalidade (98\%) dos profissionais deste estudo considera que a adolescente pode engravidar na primeira relação sexual se não utilizar o método para anticoncepção.

Pode-se observar que existe diferença de opinião entre os profissionais quanto a sua religião e sexo sobre o comportamento sexual dos adolescentes. Tais resultados vêm de encontro ao que Bozon (2004) 
refere acerca das diferenças de gênero e religião. Na prática, a moral sexual masculina é maleável para determinados comportamentos e, em todas as legislações influenciadas pelo cristianismo, o adultério sempre foi visto com um olhar muito mais severo quando dizia respeito às mulheres. $\mathrm{Na}$ cristandade medieval e clássica, excluída a busca do prazer na sexualidade lícita, ele só poderia ser experimentado na transgressão, mas se essa transgressão era amplamente tolerada para os homens, a procura do prazer pelas mulheres permanecia moralmente inaceitável.

Para Heilborn (1999), o início da atividade sexual dos homens, exprime uma mudança de status e da percepção de ser homem, sendo uma identidade de não mais criança e se integra no processo de constituição da masculinidade adulta.

Tem-se, entre alunos, pais ou professores e profissionais de saúde, comentários próprios de um discurso culpabilizante dos jovens, considerando o não uso de métodos anticoncepcionais, como irresponsabilidade.

Em estudo envolvendo crianças, adolescentes e jovens de escolas de ensino fundamental e médio de 13 capitais brasileiras e do Distrito Federal, muitos jovens, de ambos os sexos, tendem a uma apreciação negativa dos envolvidos nos casos de gravidez na adolescência. Quando falam sobre a irresponsabilidade dos jovens, enfatizam a irresponsabilidade dos pais que evitariam conversar e informar sobre a sexualidade e métodos anticoncepcionais (ABRAMOVAY; CASTRO; SILVA, 2004).

Com relação ao preservativo masculino, $100 \%$ dos enfermeiros e auxiliares de enfermagem consideram que não só os garotos como também as garotas devem tê-lo disponível no momento em que ocorrer a relação sexual, pois na falta de um o outro estará prevenido.

Estes resultados demonstram que os profissionais deste estudo concordam que a responsabilidade é de ambos os gêneros para a prevenção da gravidez, das DST e da Aids. Mas, os resultados anteriormente referidos, não vêm de encontro com esta afirmação, pois diferem das respostas anteriormente referidas de acordo com o sexo e religião. Tal diferença remete o quanto é necessário trabalhar as relações de gênero na nossa sociedade com os profissionais, pois são elas que determinam os comportamentos sexuais entre os indivíduos e grupos etários.

Segundo Rena (2001), o conceito de gênero refere-se ao imbricamento de co-determinações existentes entre o biológico e o social. A história da sexualidade no Ocidente tem sido caracterizada como fenômeno individual e biológico e objeto de estudo, sobretudo, das ciências médicas, como problema clínico e de saúde. Justamente contra esta concepção de sexualidade, o conceito de gênero possibilita tratar dos valores, das imagens e das representações, para além do biológico, presentes nas relações humanas.

Para Giffin (1995, p.8) "nesta concepção não dualista, a dimensão biológica não é determinante, nem é desconsiderada, pois o fenômeno da sexualidade é enfocado como uma interface que relaciona, dialeticamente, o biológico e o social [...]".

Quanto ao exercício de responder as questões do questionário da pesquisa, $37 \%$ da equipe de enfermagem referem ser difícil respondê-las, por não serem temas do seu cotidiano.

Tal resultado reforça, como referido anteriormente, que os profissionais que irão abordar temas pertinentes à sexualidade precisam estar desvestidos das suas próprias dificuldades de lidar com sua sexualidade para então, desenvolver ações de prevenção e atuarem como interlocutores e não repressores nas discussões sobre a temática com os adolescentes. 
Facilidades e dificuldades dos enfermeiros $e$ auxiliares de enfermagem para desenvolver ações de prevenção com adolescentes.

Com relação aos maiores problemas referentes aos adolescentes na área de abrangência da UBS, referida pelos enfermeiros e auxiliares de enfermagem, deste estudo, foram $68 \%$ a gravidez, $46 \%$ drogas e $21 \%$ as DST.

Quanto à prática da prevenção da gravidez, DST e da aids para adolescentes na UBS, 35\% dos profissionais referiram que não existe, mas $51 \%$ referem desenvolvê-la.

Dentre às facilidades para desenvolver ações de prevenção, com este grupo etário, $23 \%$ diz que possui habilidade em dar palestras e $18 \%$ ter recurso material de apoio na UBS e outros $18 \%$ o interesse dos profissionais.

Com relação às dificuldades em realizar esta atividade, $39 \%$ dos profissionais referem que o adolescente não tem interesse em participar das atividades desenvolvidas na UBS, $25 \%$ falta de material, espaço físico e tempo e $23 \%$ falta de interesse dos pais e as questões culturais.

Parece que as UBS não tem sido um espaço em que os adolescentes possam falar de sexualidade e os agravos que nela envolvam. Talvez seja necessário rever as práticas dos profissionais da saúde na abordagem de acolhimento deste grupo etário ou sair do seu espaço institucional e desenvolver um trabalho intersetorial da UBS para a escola (FERRARI, 2004).

Para $65 \%$ dos profissionais também será necessário rever o espaço físico da UBS, ter mais material de apoio e tempo para realizarem este trabalho e $31 \%$ ter mais funcionários treinados para abordar os adolescentes na temática sexualidade.

Mesmo que os enfermeiros e auxiliares de enfermagem identifiquem as dificuldades em desenvolver um trabalho com os adolescentes na UBS, $63 \%$ deles sentem-se preparados para discutir questões referentes à sexualidade.

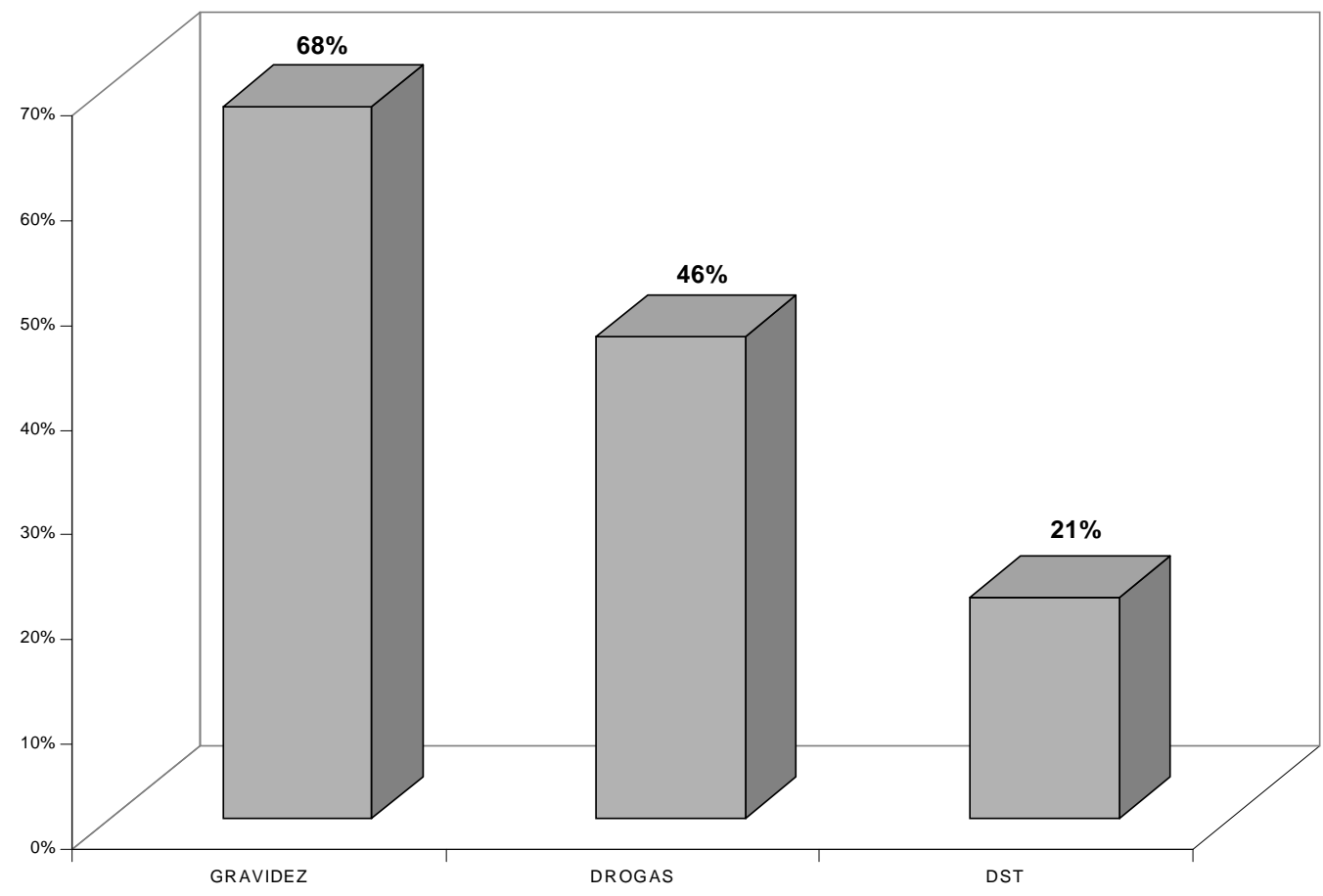

Figura 5. Distribuição dos enfermeiros e auxiliares de enfermagem quanto à identificação dos problemas de saúde entre os adolescentes na região de abrangência da UBS, Londrina, 2005. 


\section{Considerações Finais}

A pouca representatividade dos profissionais neste estudo pode estar atribuída ao tema sexualidade causando inibição pessoal ou até mesmo não ser relevante se comparado às outras temáticas de cunho biológico/fisiopatológico, por exemplo, hipertensão, diabetes, etc., que fazem parte de programas instituídos pelo Ministério da Saúde e são acatados pelos municípios. No entanto, para os adolescentes não há atividades sistemáticas no serviço de saúde e sim iniciativas individualizadas.

Quanto aos resultados deste estudo, pode-se observar diferença de opinião entre os profissionais de acordo com a religião e sexo quanto ao comportamento sexual do adolescente. Tal diferença remete o quanto é necessário trabalhar as relações de gênero na nossa sociedade, pois são elas que determinam os comportamentos sexuais entre os indivíduos e grupos etários.

Nesse sentido, a viabilidade da proposta da Educação Permanente em Saúde para os profissionais da saúde se faz necessária, visto que a mudança de comportamento só ocorrerá se forem trabalhadas as questões individuais, para posteriormente, atuarem na prevenção da gravidez não planejada, da transmissão das DST e da aids com os adolescentes, na perspectiva de interlocutores, utilizando-se discussões e reflexões para o auto-cuidado.

\section{Referências}

ABRAMO, H. W.; BRANCO, P. P. M. (Org.). Retratos da juventude brasileira: análises de uma pesquisa nacional. Instituto cidadania. São Paulo: Ed. Fundação Perseu Abramo, 2005.

ABRAMOVAY, M; CASTRO, M. G.; SILVA, L. B. da. Juventudes e sexualidade. Brasília: UNESCO, 2004.

ALMEIDA, M. C. C.; AQUINO, E. M. L.; GAFFIKIM, L.; MAGNANI, R. J. Uso de contracepção por adolescentes de escolas públicas na Bahia. Revista Saúde Pública, São Paulo, v. 37, n. 5, p. 566-75, out. 2003. Disponível em: http:/ /www.scielo.br/html. Acesso em: 26 jan.2005.
AYRES, J. C. M.; FRANÇA, JUNIOR, R. I. Saúde do adolescente. In: SCHRIBER, L. B.; NEMES, M. I. B.; GONÇALVES, R. B. M. (Org.). Saúde do adulto: programa e ações na unidade básica. São Paulo: HUCITEC, 1996. p. 67-85.

BEM ESTAR FAMILIAR NO BRASIL - BEMFAM. Adolescentes, jovens e a pesquisa nacional sobre demografia e saúde: um estudo sobre fecundidade, comportamento sexual e saúde reprodutiva. Rio de Janeiro: CDC/UNICEF, 1999.

BOZON, M.. Sociologia da sexualidade. Rio de Janeiro: Ed. FGV, 2004.

BRUNS, M. A. T.; GRASSI, M. F. C.; FRANÇA, C.. Educação sexual numa visão mais abrangente. Revista Brasileira de Sexualidade Humana, Ribeirão Preto, v. 6, n. 1, p. 60-66, mar.1995.

BRASIL. Secretaria Especial de Editoração e Subsecretaria de Edições Técnicas. Estatuto da Criança e do Adolescente. Brasília: Senado Federal, 1991.

Secretaria de Políticas de Saúde. Programa Nacional de DST e aids: dados e pesquisas em DST e aids. 2003. Disponível em: 〈http://www.aids.gov.br/htm>. Acesso em 20 dez. 2004.

DATASUS. Secretaria da Saúde de Assistência a Saúde. Informações de Saúde.1998. Disponível em: <http://www.datasus.gov.br/htm>. Acesso em: 20 ago.2005.

Conselho Nacional de Saúde. Diretrizes e normas regulamentares de pesquisa envolvendo seres humanos. Resolução nº196 de 1996. D.O.U. - Diário Oficial da União; Poder Executivo, Brasília, 1996.

BÉRIA, J. (Org.). Ficar, transar... a sexualidade do adolescente em tempos de aids. Porto Alegre: Tomo Editorial, 1998.

CAMACHO HUBNER, A. V. Perfil de Salud sexual y reprodutiva de los lãs adolescentes y jovens de América Latina y el Caribe: revisión bibliográfica, 1988 -1998. Washington: OPS, 2000.

FERRAZ, E.; FERREIRA, I. Q. Início da atividade sexual e características da população adolescente que engravida. In: SEMINÁRIO GRAVIDEZ NA ADOLESCÊNCIA, 1998, Rio de Janeiro. Anais... Rio de Janeiro: Associação Saúde da Família, 1998. p.47-57.

FERRARI, R. A. P.. Atenção à saúde dos adolescentes: ações desenvolvidas pelos médicos e enfermeiros das equipes da Saúde da Família de Londrina. 2004. Dissertação (Mestrado em Saúde Coletiva) - Universidade Estadual de Londrina, Londrina. 
FOUCAULT, M. História da sexualidade 2: o uso dos prazeres. 7.ed. Rio de Janeiro: Graal, 1984.

FURLANI, J. Educação sexual: possibilidades didáticas. In:LOURO, G. L.; NECKEL, J. F; VILODRE, S. (Org.). Corpo Gênero e Sexualidade: um debate contemporâneo na educação. Petrópolis: Vozes, 2003.

GAMA, S. G. N.; SZWARCWALD, C. L.; LEAL, M. C. Experiência de gravidez na adolescência, fatores associados e resultados perinatais entre puérperas de baixa renda. Cadernos da Saúde Pública, Rio de Janeiro. v.18, n.1, p.153-161, jan./fev.2002. Disponível em: <http:// www.scielo.br/html> Acesso em: 26 jan.2004.

GUIMARÃES, A. M. A. N.; VIEIRA, M. J.; PALMEIRA, J. A. Informações dos adolescentes sobre métodos anticoncepcionais. Revista Latinoamericana de Enfermagem, Ribeirão Preto, v.11, n.3, p.293-298, maio/ jun.2003. Disponível em: <http://www.scielo.br/html>. Acesso em: 26 jan.2005.

GIFFIN, K. Gênero e saúde. Curitiba: ABRASCO/NESCO, 1995. Curso ministrado no I Congresso Brasileiro de Ciências Sociais e Saúde - PR.

HEILBORN, M. L. Construção de si , gênero e sexualidade. In: ____ (Org.). Sexualidade: o olhar das ciências sociais. Rio de Janeiro: Jorge Zahar, 1999.

HEILBORN, M. L.; BRANDÃO, E. R. Ciências sociais e sexualidade. In: HEILBORN, M. L. (Org.). Sexualidade: o olhar das Ciências Sociais. Rio de Janeiro: Jorge Zahar, 1999.

HUERTAS, L. L. R.. Reforma sanitária, promocion de la salud y programas de salud de los adolescentes em la region: casos de Brasil, Costa rica y República Dominicana. Washington: OPS, 2001.

JEOLÁS, L. S. O jovem e o imaginário da aids: o bricoleur de suas práticas e representações. 1999. Tese (Doutorado em Antropologia) - Pontifícia Universidade Católica, São Paulo.

JEOLÁS, L. S.; FERRARI, R. A. P. Oficinas de prevenção em um serviço de saúde para adolescentes: espaço de reflexão e de conhecimento compartilhado. Revista Ciência e Saúde Coletiva, São Paulo, v.8, n.2, p.611-620, 2003.

LONDRINA. Secretaria Municipal de Saúde. Diretoria de Assistência à Saúde. Dados do SIAB: Londrina 2004. Londrina: a Secretaria, 2005.

LONDRINA. Secretaria Municipal de Planejamento. Síntese do perfil do município de Londrina 2004: baseado nos dados de 2003. Disponível em: <http:// www.londrina.pr.gov.br/perfil2003.htm> Acesso em $10 \mathrm{fev}$. 2005.
LOYOLA, M. A. A sexualidade como objeto de estudo das ciências humanas. In. HEILBORN, M. L. (Org.). Sexualidade: o olhar das Ciências Sociais. Rio de Janeiro: Jorge Zahar, 1999.

LURNADELLI, J. L. Anticoncepção na adolescência. Rev. Pediatria Moderna, São Paulo, v.38, n.8, Ed. esp., p. 381387, ago. 2002.

MONTEIRO, S. Aids, sexualidade e gênero: a lógica da proteção entre jovens de um bairro popular carioca. 1999. 212 f. Tese (Doutorado em Saúde Pública) - Escola Nacional de Saúde Pública, Rio de Janeiro.

OLIVEIRA, D. L. O fenômeno da sexualidade adolescente: conceito, contextualização e análise. Revista Gaúcha Enfermagem, Porto Alegre, v.16, n.1/2, p. 94-97, jan/dez. 1995.

OLIVEIRA, R. L. C. Estudo sobre conhecimento de doenças sexualmente transmissíveis e comportamento sexual de adolescentes do ensino médio de escolas públicas de Londrina, 2002. Dissertação (Mestrado em Saúde Coletiva) - Universidade Estadual de Londrina, Londrina.

ORGANIZACIÓN MUNDIAL DE LA SALUD. La salud de los jovens: um reto y uma esperanza. Genebra: OMS, 1995.

OUTEIRAL, J. O. Adolescer: estudos sobre adolescência. Porto alegre: Artes Médicas Sul, 1994.

PAIVA, V. Sexualidade e gênero num trabalho com adolescentes para prevenção do HIV/Aids. In: PARKER, R.; GALVÃO, J.; PEDROSA, J. S. (Org.). A aids no Brasil (1982-1992). Rio de Janeiro: ABIA, 1994.

PAIVA, V.; VENTURI, G.; FRANÇA JUNIOR, I.; LOPES, F. Uso de preservativos: pesquisa nacional MS/Ibope, Brasil. 2003. Disponível em: 〈http://www.aids.gov.br/htm>. Acesso em 20 out. 2005.

RENA, L. C. C. B. Sexualidade e adolescência: as oficinas como prática pedagógica. Belo Horizonte: Autêntica, 2001. (Coleção Trajetória).

SIMÕES, V. M. F.; SILVA, A. A. M.; BETTIOL, H.; LAMY FILHO, F.; TONIAL, S. R.; MOCHEL, E. G. Características da gravidez na adolescência em São Luiz, maranhão. Revista de Saúde Pública, São Paulo, v.37, n.5., p.559-65, out. 2003. Disponível em: <http://www.scielo.br/htm>. Acesso em: 23 jan. 2004.

SILVA, W. A.; BUCHLLAA, C. M.; PAIVAH, V.; LATORREA, M. R. D. O.; STALLC, R.; HEARSTD, N. Prevenção de doenças sexualmente transmissíveis e aids em jogadores juniores. Revista de Saúde Pública, São Paulo, v.36, n.supl.4, p.68-75, 2002. 
SZWARCWALD, C. L.; CASTILHO, E. A.; BARBOSA JUNIOR, A.; GOMES, M.R. O.; COSTA, E. A. M.; MALETTA, B. V.; CARVALHO, R. F. M.; OLIVEIRA, S. R.; CHEQUER, P. Comportamento de risco dos conscritos do exército brasileiro: uma apreciação da infecção pelo VIV segundo diferenciais sócio-econômicos. Cadernos de Saúde Pública, Rio de Janeiro, v.16, supl.1, p.113-128, 2000.
VILLELA, W. V.; ARILHA, M. Sexualidade, gênero e direitos sexuais e reprodutivos. In: BERQUÓ, E. (Org.). Sexo e vida: panorama da saúde reprodutiva. Campinas: Unicamp, 2003. p.97. 